\title{
0 desafio de compreender a consequência fatal da violência em dois municípios brasileiros
}

\author{
Juliana Guimarães e Silva ${ }^{1}$ \\ Fabiana Castelo Valadares ${ }^{2}$ \\ Edinilsa Ramos de Souza ${ }^{3}$
}

\begin{abstract}
GUIMARÃES E SILVA, J.G.; VALADARES, F.C.; SOUZA, E.R. The challenge of understanding the fatal consequences of violence in two Brazilian municipalities. Interface (Botucatu), v.17, n.46, p.535-47, jul./set. 2013.
\end{abstract}

It was sought to understand murders through a complex systemic approach by applying the ecological model, which involves the individual and relational conditions of the subjects and context. Two cases were studied, with triangulation of quantitative and qualitative data. The municipalities selected (Paulista, Pernambuco, and Jaraguá do Sul, Santa Catarina) showed opposite behavior in relation to homicide rates between 1980 and 2007. Qualitative analyses revealed the following, for each dimension of the ecological model: individual: low education level and drug use; relational: domestic violence and drug use by family members; social and community: work and unemployment; public education; public security; drug trafficking; and religiosity. It was concluded that homicides involve combinations of vulnerability, precariousness and breakage of bonds within the individual and social dimensions. These issues can be addressed through an inclusive, interdisciplinary and intersectoral perspective.

Keywords: Homicide. Case study. Violence. Social vulnerability.
Buscou-se compreender os homicídios por meio da abordagem sistêmica complexa aplicando-se o Modelo Ecológico (ME), que envolve condições individuais e relacionais dos sujeitos e do contexto. Foram realizados dois estudos de caso triangulando dados quantitativos e qualitativos. Os municípios selecionados, Paulista, Pernambuco, e Jaraguá do Sul, Santa Catarina, apresentaram comportamentos opostos em relação às taxas de homicídios entre 1980 e 2007 . Na análise qualitativa, descortinou-se, em cada dimensão do modelo ecológico: individual - baixa escolaridade e uso de drogas; relacional violência intrafamiliar e uso de drogas por membros da família; comunitário e social - trabalho e desemprego; educação pública - segurança pública; tráfico de drogas e religiosidade. Conclui-se que os homicídios envolvem a combinação de vulnerabilidades, precariedades e rupturas de vínculos na dimensão individual e social, passíveis de enfrentamento em uma perspectiva inclusiva, interdisciplinar e intersetorial.

Palavras-chave: Homicídio. Estudos de casos. Violência. Vulnerabilidade social.

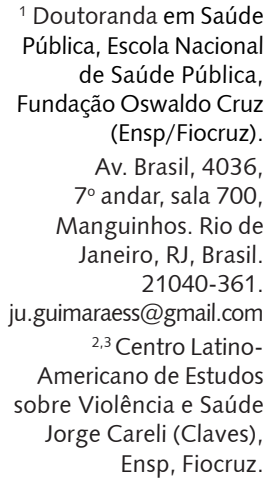

1 Doutoranda em Saúde Pública, Escola Nacional de Saúde Pública, Fundação Oswaldo Cruz (Ensp/Fiocruz). Av. Brasil, 4036, $7^{\circ}$ andar, sala 700 , Manguinhos. Rio de Janeiro, RJ, Brasil. 21040-361. ju.guimaraess@gmail.com ${ }^{2,3}$ Centro LatinoAmericano de Estudos sobre Violência e Saúde Jorge Careli (Claves), Ensp, Fiocruz. 


\section{Introdução}

O homicídio, uma das múltiplas expressões da violência e seu indicador universal, é caracterizado como a morte que ocorre por agressão, independentemente da sua tipificação legal. No Brasil, o homicídio contribuiu para o aumento significativo das mortes por causas violentas, no conjunto dos óbitos por todas as causas, desde o final da década de 1980. Só a partir de 2003 observou-se uma inflexão das taxas de mortalidade por homicídio (TMH), em municípios como São Paulo e Rio de Janeiro, e em outras áreas urbanizadas do país; e a primeira década dos anos 2000 foi marcada pela denominada interiorização da violência, que se caracteriza pelo incremento das TMH nos municípios do interior dos Estados (Peres et al., 2011; Rechenheim et al., 2011; UNODOC, 2011; Waiselfisz, 2011; Souza, Lima, Bezerra, 2010).

Considerado um fenômeno complexo, o homicídio se distribui de forma heterogênea e tem sido estudado, sobretudo, por meio de abordagem quantitativa, na qual se analisam: sua distribuição segundo áreas, grupos populacionais mais afetados e sua tendência no tempo (Andrade et al., 2011; Rechenheim et al., 2011; Sant'anna, Aerts, Lopes, 2005). Mesmo os estudos que buscam explicá-lo em sua complexidade, considerando o contexto em que ocorrem, ainda são incipientes e também priorizam enfoques quantitativos (Duarte et al., 2012; Meneguel, Hirakata, 2012; Peres et al., 2012; Andrade et al., 2011; Peres et al., 2011).

Estudiosos do tema têm proposto modelos explicativos que captem os aspectos qualitativos dessa violência, tentando abordá-la com uma visão compreensiva (Briceño-Leon, 2005, 2002). Uma dessas iniciativas é o Modelo Ecológico adotado pela Organização Mundial de Saúde. Tal modelo se fundamenta na multicausalidade da violência e analisa as inter-relações entre condições individuais e contextuais, considerando que ela resulta da influência de quatro diferentes dimensões: (a) individual, que focaliza as características do indivíduo que podem favorecer sua implicação em atos violentos (condições biológicas, demográficas, abuso de substâncias, dentre outras); (b) relacional, que identifica como a vitimização ou perpetração da violência pode ser influenciada pelas relações sociais próximas (família, parceiros íntimos, amigos); (c) comunitária, que focaliza as condições dos cenários em que se dão as relações e que possibilitam o envolvimento com a violência (escolas, locais de trabalho, vizinhança); e (d) social, que analisa as condições sociais e culturais mais amplas que influenciam os índices de violência (políticas de saúde, educacionais, econômicas e sociais) (OMS, 2002).

Neste artigo pretende-se compreender o fenômeno dos homicídios por meio da abordagem dos sistemas sociais complexos (Luhmann, 2006), a partir de um estudo empírico que combina o método quantitativo e qualitativo e utiliza o Modelo Ecológico como fio condutor.

\section{Metodologia}

A pesquisa que originou este artigo investigou o impacto dos homicídios em quatro países da América Latina - Brasil, Argentina, Colômbia e México. Envolveu um estudo epidemiológico e estudos de caso com o objetivo de obter uma visão complexa do objeto de investigação. Assim, as abordagens quantitativa e qualitativa foram combinadas na perspectiva da triangulação de métodos (Minayo, Assis, Souza, 2005). Neste texto faz-se um recorte da pesquisa original e apresenta-se a análise qualitativa dos dois estudos de caso realizados no Brasil.

Os critérios de escolha dos municípios estudados, definidos na etapa quantitativa do estudo, foram: (1) população superior a cem mil habitantes, excluindo-se as capitais; (2) possuir dados de mortalidade por homicídios disponíveis para o período de 1980 a 2007, e (3) apresentar diferentes comportamentos em relação às TMH: um com aumento da taxa de mortalidade por homicídios mesmo com piora da qualidade da informação (grupo de óbitos por lesões ignorado intencionalmente); e o outro com queda da TMH, mesmo com melhora da qualidade da informação. Considerando-se o último triênio analisado, foram selecionados Jaguará do Sul/SC, com a menor TMH, e Paulista/PE, com a maior taxa. Para esses municípios, foram coletados indicadores como: Índice de Desenvolvimento Humano, Índice de Gini, proporção de pobres, taxa de analfabetismo, taxa de desemprego, taxa de mortalidade geral e por 
homicídios, dentre outros. As fontes pesquisadas foram o Censo 2010 realizado pelo IBGE e o Sistema de Informação sobre Mortalidade/SIM.

Buscou-se identificar e compreender as condições que, sob a ótica dos atores locais, podem influenciar a ocorrência e a dinâmica dos homicídios, considerando-se as dimensões do modelo ecológico (OMS, 2002). Foram investigadas as percepções dos sujeitos acerca dos homicídios no seu município, indagando-Ihes sobre: as suas explicações para a ocorrência deste fenômeno; a realização de ações institucionais voltadas à prevenção destes eventos, e as iniciativas que poderiam ser implementadas para reduzi-los.

Entre novembro e dezembro de 2010, foram realizadas 12 entrevistas individuais semiestruturadas e 12 grupos focais. Foram entrevistados: gestores da segurança pública e da assistência social, prefeitos, conselheiros tutelares, policiais e lideranças comunitárias. Dos grupos focais participaram: profissionais da estratégia saúde da família, jovens religiosos e em conflito com a lei, professores e estudantes de escolas públicas, e familiares de jovens, totalizando 64 informantes-chave. Os depoimentos foram gravados com a autorização dos sujeitos, transcritos e checados quanto à fidedignidade do relato oral.

A análise seguiu as etapas de pré-análise, exploração do material, tratamento dos resultados e interpretação (Minayo, 2006). Na pré-análise, foi feita a leitura flutuante dos relatos e a constituição do corpus no qual se pautou a comparação entre os municípios. Na exploração do material, os agrupamentos e categorizações dos textos foram ancorados nas dimensões do modelo ecológico. Foram identificados como temas as dimensões: individual, relacional, comunitária e social. Em cada um deles, emergiram as seguintes categorias: (i) individual: escolaridade e uso de drogas; (ii) relacional: família, violência intrafamiliar e entre parceiros íntimos, e uso de drogas por membros da família, e (iii) comunitárias e sociais: trabalho e desemprego, educação pública, segurança pública, tráfico de drogas e religiosidade. Na fase de análise e interpretação, foram identificadas semelhanças e singularidades dos municípios (Minayo, 2006). A triangulação dos dados qualitativos e quantitativos foi feita sempre que possível, e a discussão foi realizada com base na literatura pertinente. Os depoimentos dos sujeitos foram identificados nas seguintes categorias: gestor, profissional, familiar e jovem, com vistas a garantir o anonimato dos participantes. A pesquisa original foi aprovada pelo Comitê de Ética da Escola Nacional de Saúde Pública Sérgio Arouca/Fiocruz.

\section{Resultados}

\section{Diferenciais socioeconômicos e demográficos dos cenários estudados}

Situada no Nordeste brasileiro, Paulista, a cidade com maiores TMH, compõe a região metropolitana do Recife/PE. Jaraguá do Sul, aquela com as menores taxas, integra a área metropolitana de Joinville, no interior do Estado de Santa Catarina. Ambas têm o histórico de ocupação de seu território relacionado à colonização do país nos séculos XVI e XVII, respectivamente. Desenvolveram-se a partir da presença de proprietários de terras que nelas se instalaram e passaram a produzir produtos agrários e extrativistas para a colônia. Em Paulista, esta produção foi gradualmente substituída pela indústria ligada à tecelagem. Em Jaraguá do Sul, houve uma maior diversificação da produção industrial, fundada em torno do engenho de açúcar, serraria e olaria, e, mais tarde, pelas atividades dos setores de alimentos.

Ambas foram emancipadas durante a década de 1930, e registraram incremento industrial durante os anos de 1970. Há informações de forte fluxo imigratório em Paulista nesse período, relacionado à presença de trabalhadores de toda a região Nordeste que buscavam emprego formal em seu distrito industrial. Por sua vez, Jaraguá do Sul registrou forte presença de imigrantes estrangeiros, ainda na década de 1890. Paulista vivenciou uma forte crise econômica de 1980 a 1990, com o fechamento das fábricas e o desemprego de sua população, que perdura até o presente. Em Jaraguá do Sul, a diversificação da economia preservou a cidade dos grandes impactos da crise econômica brasileira que emergiu com o fim do milagre econômico dos anos 1960.

Paulista possui maior população e densidade demográfica $\left(2.974 / \mathrm{Km}^{2}\right)$ que Jaraguá do Sul (269/ $\mathrm{Km}^{2}$ ). Na primeira, no ano de 2011, os 300.466 habitantes concentravam-se na faixa etária de 18 a 
quarenta anos. Entre os 143.123 habitantes de Jaraguá do Sul, predominava o grupo de vinte a 49 anos de idade, no mesmo ano. Além de concentrar sua população numa faixa etária mais velha, Jaraguá do Sul também possuía distribuição mais equitativa entre os sexos: os homens representavam 49,9\%, percentual maior que o observado em Paulista $(47,2 \%)$.

Na Tabela 1, observam-se grandes disparidades nos indicadores sociais das duas cidades, segundo dados do Instituto Brasileiro de Geografia e Estatística/IBGE (IBGE, 2010). De forma geral, Paulista apresenta os piores indicadores socioeconômicos. Em 2010, o índice de Gini, o IDH e o PIB de Jaraguá do Sul se mostraram substancialmente melhores do que em Paulista. Nessa última, se observa a deterioração da renda per capta média em reais, que corresponde à metade dos rendimentos encontrados em Jaraguá do Sul.

No mesmo período, Paulista concentrou as piores condições materiais de vida e maior instabilidade econômica, apresentando elevada proporção de pobres e taxas de desemprego em maiores de 16 anos, quase seis vezes maiores que a de Jaraguá do Sul e duas vezes superior à do Brasil. A taxa de analfabetismo para maiores de 15 anos em Paulista foi muito superior à registrada em Jaraguá do Sul e quase quatro vezes maior que a taxa brasileira. Quanto aos indicadores de trabalho e rendimento, em Paulista predomina o subemprego, representado pela elevada proporção da população que exerce atividades laborais sem carteira assinada.

Tabela 1. Indicadores socioeconômicos e demográficos de Paulista, Jaraguá do Sul e Brasil

\begin{tabular}{|c|c|c|c|}
\hline Indicadores & Paulista & Jaraguá do Sul & Brasil \\
\hline Índice de Desenvolvimento Humano (2000) & 0,799 & 0,855 & 0,747 \\
\hline Índice de Gini (2000) & 0,55 & 0,38 & 0,602 \\
\hline Produto Interno Bruto - PIB (R\$ mil) (2009) & 52.609 & 4.697 .090 & 3.239 .404 .053 \\
\hline Proporção de pobres (2010) & 54,1 & 4,3 & 20,02 \\
\hline Proporção da população de baixa renda & 39,62 & 5,78 & 34,67 \\
\hline \multicolumn{4}{|l|}{ Habitação (2010) } \\
\hline Água encanada & 98,03 & 99,62 & 94,23 \\
\hline Energia elétrica & 99,92 & 99,96 & 98,73 \\
\hline Coleta de lixo & 91,04 & 99,40 & 87,41 \\
\hline Domicílios com geladeira & 96,98 & 99,12 & 93,68 \\
\hline Domicílios com computador (2000) & 37,22 & 58,45 & 38,31 \\
\hline \multicolumn{4}{|l|}{ Educação (2010) } \\
\hline Taxa de analfabetismo para 15 ou mais anos & 32,2 & 1,8 & 9,6 \\
\hline Proporção de pessoas que frequentavam escola ou creche & 30,78 & 29,66 & 31,23 \\
\hline Proporção de pessoas que frequentavam a rede de ensino pública & 17,14 & 22,09 & 24,39 \\
\hline Proporção de pessoas que frequentavam a rede de ensino privada & 13,65 & 7,57 & 6,84 \\
\hline Proporção de pessoas que nunca frequentaram escola ou creche & 7,08 & 4,71 & 9,82 \\
\hline Proporção de pessoas no Ensino Fundamental & 48,89 & 42,41 & 51,62 \\
\hline Proporção de pessoas no Ensino Médio & 19,59 & 18,66 & 17,79 \\
\hline Proporção de pessoas no Ensino Superior & 11,29 & 14,51 & 10,40 \\
\hline Proporção de pessoas dos 4 aos 19 anos que frequentavam escola & 73,32 & 66,40 & 74,69 \\
\hline \multicolumn{4}{|l|}{ Trabalho e rendimento } \\
\hline Taxa de desemprego de pessoas com 16 e mais anos & 14,36 & 2,68 & 7,42 \\
\hline Proporção de pessoas empregadas com carteira assinada & 52,53 & 72,24 & 45,29 \\
\hline Proporção de pessoas empregadas sem carteira assinada & 19,25 & 7,10 & 20,17 \\
\hline Rendimento médio mensal de pessoas com 10 ou mais anos (em reais) & 948,87 & $1.058,70$ & $1.344,70$ \\
\hline Renda per capta média em Reais (2010) & 507,98 & $1.091,86$ & 767,02 \\
\hline \multicolumn{4}{|l|}{ Saúde } \\
\hline Taxa de Mortalidade Geral por 100.000 hab. (2009) & 492,8 & 504,3 & 576,0 \\
\hline Taxa de Mortalidade Infantil por 1.000 nascidos vivos (2007) & 12,6 & 7,7 & 20,0 \\
\hline Taxa de Mortalidade por Causas Externas por 100.000 hab. (2009) & 72,6 & 63,3 & 72,4 \\
\hline Taxa de homicídios por 100.000 hab. (2009) & 42,6 & 5,0 & 26,8 \\
\hline Unidades de Saúde no município (2007) & 119 & 296 & 170.979 \\
\hline Unidades de Saúde da Família (2007) & 40 & - & 30.163 \\
\hline
\end{tabular}

Fonte: DATASUS/IBGE 
Os indicadores de mortalidade não discrepam tanto. No entanto, diferem quanto à taxa de mortalidade infantil, que, em Paulista, é quase duas vezes maior que em Jaraguá do Sul, e em relação às taxas de homicídios, que, no primeiro, mostram-se 8,5 vezes maior que a de Jaraguá do Sul e 1,6 vezes superior à do Brasil, em 2009.

\section{Abordagem das condições individuais e contextuais na busca de uma visão compreensiva dos homicídios}

Poucas foram as diferenças relatadas pelos informantes das duas cidades, acerca das condições individuais relacionadas aos homicídios. A baixa escolaridade dos autores e das vítimas dessa violência configurou-se como a principal distinção, com os moradores de Paulista associando-a ao uso de drogas e à criminalidade:

\footnotetext{
"Se você fizer um levantamento do nível de escolaridade dessas pessoas que cometem homicídio, são pessoas que geralmente se envolvem com baixíssima escolaridade, começam na vida do crime, a partir das drogas e daí, depois começam a se, nesse envolvimento, a cometer os crimes". (Gestor - Paulista)
}

Além disso, a baixa escolaridade também foi apontada em Paulista como condição que dificulta o acesso da população ao mercado de trabalho formal.

O envolvimento com drogas foi também referido por grande parte dos entrevistados nas duas cidades, mais enfaticamente em Paulista, como uma situação de risco para homicídios em função da dificuldade financeira de sustentar o vício:

“Eu fumo, aí eu vou pegar pra vender, aí eu vou fumar e ficar devendo, dinheiro eu não vou ter, ele vai querer me matar, entendeu, é por isso que eu não pego pra vender, sabendo que eu fumo". (Jovem - Paulista)

“[...] aqui em Jaraguá a gente ouve pouco falar em homicídio, mas sempre quando ouve é passional. [...] ou é dívida de dinheiro, talvez tenha alguma coisa de droga. Isso a gente não sabe, mas a gente escuta falar que devia 20 reais, 50 reais e foi cobrar, brigaram e um esfaqueou o outro". (Profissional - Jaraguá do Sul)

Observa-se, pelos relatos, que, em Jaraguá do Sul, a ocorrência dos homicídios é também atribuída a causas passionais ou dívida de dinheiro que podem envolver a questão das drogas. Já em Paulista, as drogas, especialmente o crack, são mencionadas como justificativa central para os assassinatos. Para os entrevistados, o uso abusivo de drogas e de álcool estaria associado à perda de consciência e aumento dos impulsos agressivos, sendo este o motivo do risco: "Porque quando os homicídios acontecem é porque realmente eles estão envolvidos, tomados pela droga" (Gestor - Paulista).

Ao se considerar a contribuição das condições relacionais na ocorrência dos homicídios, os depoentes, com distintas percepções, destacaram as relações familiares. Em Jaraguá do Sul, os vínculos familiares foram muito valorizados e qualificados como sólidos. A família foi citada como o principal meio de socialização e lazer, sendo, nesse caso, considerada como protetora:

\footnotetext{
"Então a gente aprende que família é importante. Então a gente cresceu, nós crescemos dentro de uma família estruturada e a gente passa isso para os filhos. Eles sabem a importância de ter uma estrutura boa na família. Quando eles tiverem seus filhos eles vão querer para eles aquilo que eles tiveram". (Gestor - Jaraguá do Sul)
}

Em Paulista, a "família desestruturada", a falta de planejamento familiar e o machismo configuraramse como risco para os homicídios. Os profissionais relataram, frequentemente, a fragilidade dos vínculos familiares e as situações de abandono e negligência por parte dos pais. A violência intrafamiliar foi 
enfatizada pelos profissionais e gestores, o que pode redundar na reprodução do seu ciclo (Cavalcante, Schenker, 2009).

"A violência dentro de casa, né, são jovens, na maioria das vezes que, são os jovens que não tem respeito, dentro de casa não tem a questão da atenção, não receberam amor, também, aquela questão, da educação, falo educação de casa mesmo, né, são pais que simplesmente não planejaram a vinda do filho, então são pessoas que têm um laço afetivo fragilizado, né, são adolescentes que são criados em meio a conflitos, a confusões, a palavrões, não existe aquele respeito com a pessoa". (Profissional - Paulista)

Nas duas cidades, a violência entre parceiros íntimos e o ciúme foram retratados por gestores e profissionais como associados aos homicídios:

"A gente observa o caso, como foi passado, de padrastos, a gente passou uma época em Paulista, que enfim, que matavam mulheres assim, de diversas idades, aí vinha pela linha do abuso sexual, né, da violência sexual, do estupro seguido de morte". (Gestor - Paulista)

"[...] aconteceu de uma mulher que o marido assassinou. Teve um que chamou muita atenção que foi de um padrasto que esfaqueou a enteada. A princípio, ele diz que ela não obedecia ele. Ele mandava ela lavar louça e ela não foi. Corre pela cidade que ele tentou abusar dela e ela reagiu e aí ele acabou fazendo isso". (Profissional - Jaraguá do Sul)

O uso de drogas por membros da família foi mencionado pelos sujeitos em Paulista como uma das principais condições relacionais que contribuem para condutas como abuso de substâncias ilícitas, envolvimento com crimes e para a ocorrência de homicídios:

"A família errada, a família errada, não vai fazer nada [...] aquele negócio, né, mãe cachaceira, pai cachaceiro, filho drogado, não vai ter [...] ter uma mãe em casa para chegar perto do filho desse jeito não vai dar, [...] é filho solto na rua e geralmente o pai e a mãe ficam pouco em casa, e aí, o filho pode ter 10 anos, mas chega aí, vamos matar". (Jovem Paulista)

Entre as condições comunitárias e sociais, foram relatados, pelos entrevistados, como associados aos homicídios: trabalho/desemprego; educação pública; segurança pública; tráfico de drogas e religiosidade. A forma de organização e estruturação do trabalho é bem distinta entre as cidades. Em Paulista, o vínculo formal de trabalho é escasso e as atividades são mal remuneradas, como apontam os indicadores sociais apresentados. As estratégias de inserção no mercado de trabalho são permeadas pelas atividades ilícitas, nas quais o tráfico de drogas e a exploração sexual foram muito relatados pelos jovens. Esta realidade influencia na baixa qualidade de vida dos moradores: "Os pobres, o pobre, a pobreza, a classe mais baixa, quanto menos pobre, melhor, que se ele está, com a família que vai estar e roubar, pela necessidade de, às vezes, de não ter dinheiro" (Jovens - Paulista). Em Paulista, a proporção de pobres chega a 54,1\% e a taxa de desemprego de maiores de 16 anos foi de 14,36\% em 2010.

Em Jaraguá do Sul, a vivência do pleno emprego se reflete em uma sociedade que valoriza a aquisição do poder econômico pela via do trabalho formal no setor industrial. No município, em 2010, a proporção de pobres foi de 4,3\%, e um total de $72,24 \%$ dos trabalhadores possuía carteira assinada, dados que corroboram os relatos dos sujeitos. Os jovens moradores afirmam que a rotina é mais restrita, com horários definidos e espaços de lazer restritos em função das atividades laborais:

“Talvez a estrutura empresarial por ter um número mais elevado de emprego, que faz com que diminua o número de homicídios. Aqui o pessoal trabalha muito e não tem tempo para pensar nisso. Tem muita oportunidade de emprego e não trabalha quem não quer, tem muito emprego". (Jovens - Jaraguá do Sul) 
No contexto de trabalho, majoritariamente industrial e formal, em Jaraguá se produziu um pacto coletivo que atribui às instituições, públicas e privadas, a excelência da qualidade dos serviços prestados e a confiança de que são capazes de exercer adequadamente as suas funções. Isto se reflete na qualidade dos serviços públicos em que urbanização, saneamento, saúde, educação e segurança pública são bem avaliados. Há um processo de responsabilização dos moradores que visa à promoção da qualidade de vida e demonstra uma elevada consciência e controle social: "[...] o investimento social, saúde e, principalmente, educação é que no decorrer dos anos dão esse quadro favorável para Jaraguá do Sul que eu acredito que serão ainda melhores no futuro" (Gestor - Jaraguá do Sul).

Já em Paulista, o caráter majoritariamente informal (19,25\% da população trabalhava sem carteira assinada em 2010), e, às vezes, ilegal das atividades laborais parece fragilizar os vínculos sociais e a confiança nas instituições. Além do que, a informalidade do trabalho produz bens e serviços sem fiscalização e sem controle da qualidade do que é ofertado.

A educação pública foi qualificada pelos entrevistados, em Paulista, como um serviço de má qualidade. Tal compreensão, também evidenciada nos indicadores sociais, converge para os relatos dos grupos de jovens que atribuem à evasão escolar a precariedade deste setor. Para eles, permanecer na escola é uma iniciativa individual, já que, muitas vezes, não há professores, os cronogramas de aula não são cumpridos e a estrutura física das escolas não é priorizada pelos gestores:
"pode ser no colégio, pode ser fora, a gente não sabe o que está acontecendo nas salas, não tem todas as aulas. Chega numa, não tem todas as aulas; chega, o professor não veio e como não tem todas as aulas, não dá nem para saber do colégio". (Jovens - Paulista)

A segurança pública foi apontada como um fator importante para a ocorrência de homicídios em Paulista. Os presídios dos municípios vizinhos, ao oferecerem indulto em datas comemorativas e regimes semiabertos, parecem contribuir para a ocorrência de crimes e mortes. Segundo parte dos entrevistados, nos finais de semana e em datas comemorativas, aumentam o número de crimes e a sensação de insegurança dos moradores. Foi muito relatada, pelos sujeitos mais expostos à violência, como os jovens abrigados, seus familiares e pelos estudantes, a presença de grupos armados envolvendo policiais que ofertam segurança particular e formam "grupos de extermínio" responsáveis por mortes na comunidade:

"Uns morrem de bala perdida, os homens também contribuem pros que tão aí morrer, os próprios policial. O próprio policial que tem grupo de extermínio por aí. Se disfarçam de segurança de loja, aí fica só visando os que estão furtando, até pra roubar o litro de um leite, pra roubar, pra dar o que comer a família, quer saber não, mete o dedo mesmo, "tora", e mata mesmo, o próprio policial, se junta com os outros aí, os colegas, e tira onda". (Jovens Paulista)

Na dimensão comunitária e social, o tráfico de drogas e o envolvimento com seus usuários aparecem na visão dos entrevistados com um papel fundamental na ocorrência dos homicídios em ambas as cidades. Em Paulista, o tráfico surge como uma forma de ocupação rentável que acena com a possibilidade, sobretudo para o jovem, de consumir bens e produtos valorizados no mundo contemporâneo:

\footnotetext{
"O traficante oferece outras coisas que a mãe não pode dar, que a mãe não pode oferecer, como celular, como roupa, como uma corda, eles chamam de corda aquele negócio que fica no pescoço. Aí ele vê aquele cidadão todo bonzinho, dando tudo isso a ele, então ele vai fazer o que aquele cidadão deseja que faça, porque aquele cidadão que faz tudo por ele, enquanto em casa não tem quem faça". (Profissional - Paulista)
}

A religiosidade foi apontada como recurso para a proteção contra os homicídios nas duas cidades, porém com menor expressão em Paulista. Um dos entrevistados informou que a falta de trabalhos da 
igreja com jovens tem contribuído para a cooptação destes pelo crime organizado. Já no relato dos jovens religiosos, o caráter preventivo da religiosidade é efetivo, pois oferta possibilidades positivas de lazer e de relações sociais: "Uma pessoa jovem chega na igreja diferente a gente vai lá, faz um contato, sai com a gente para ver como é que faz, a pessoa se sente a vontade, então a gente faz vários passeios, ao ar livre" (Jovens - Paulista).

Os jovens religiosos de Paulista realçaram que as atividades de lazer comuns na cidade, como festas culturais, casas noturnas e praias, são também os cenários preferenciais para a ocorrência de homicídios. Um grupo de profissionais reforça o relato destes jovens ao afirmar que tais eventos acontecem frequentemente e, como há diferentes grupos armados na cidade, tornam-se espaços de encontro e conflito entre eles:

\begin{abstract}
"A maioria desses homicídios é cometido em outras situações, né, em situações que quando eles saem para discotecas e também de drogas, tem problemas que envolvem questões particulares deles, de traições, então esses homicídios são cometidos, questão de galeras, dos encontros, um bate no amigo do outro, um bate, o outro foi vítima de uma agressão". (Profissional - Paulista)
\end{abstract}

Em Jaraguá do Sul, a religiosidade, como um traço fundante de uma "índole pacífica" e temente a Deus, foi defendida pelos entrevistados como responsável pela cultura de paz, atribuída ao "povo alemão": "Acho que o povo Jaraguense é muito religioso. Toda religião tem um grupo específico e eu acho que isso faz com que cada pessoa tenha essa base. Tanto que o município dá total apoio à igreja" (Jovens - Jaraguá do Sul). A forte atuação das igrejas locais nas ações de apoio social e tratamento de usuários de drogas, voltada para a reclusão, foi relatada como iniciativa relevante no município.

\title{
Discussão
}

A fim de obter uma visão compreensiva dos homicídios nos municípios estudados, ao mesmo tempo complexa e triangulada, analisam-se as percepções dos informantes tomando-se as dimensões individual, relacional, comunitária e social definidas pelo modelo ecológico, contextualizando-as, sempre que possível, com os indicadores socioeconômicos e demográficos dessas respectivas dimensões de determinação.

$\mathrm{Na}$ dimensão individual, a baixa escolaridade foi associada às altas TMH pelos entrevistados em Paulista. Embora alguns estudos mostrem que essa condição é comum entre vítimas e autores de homicídios (Sá, Werlang, 2007), não se pode afirmar que há, entres elas, uma relação direta. Os indicadores educacionais, para 2010, mostram que, em Paulista, a taxa de analfabetismo de jovens com 15 anos ou mais foi 17,9 vezes maior que a de Jaraguá, e que a proporção de pessoas que nunca frequentaram a escola foi de 7,08\% em Paulista e 4,71\% em Jaraguá. Tais disparidades nestes indicadores apontam uma situação de exclusão marcante em Paulista, caracterizada, também, pela privação de acesso à educação de grande parcela da população, que acarreta dificuldades de inserção no mercado de trabalho formal.

Verifica-se que, em Paulista, a taxa de desemprego de pessoas com 16 anos ou mais de vida e a taxa de trabalho informal (sem carteira assinada) eram, respectivamente, 5,3 e 2,7 vezes maiores que as de Jaraguá do Sul, em 2010, o que repercute sobre as condições de vida, colabora para a manutenção das desigualdades e pode resultar em violências, particularmente em homicídios. Ressalta-se que diferentes formas de exclusão conduzem a uma violência difusa que se associa a um estado de desagregação e decomposição social (Minayo-Gomez, Thedim-Costa, 1999).

Considerando-se o tema das drogas, os profissionais e jovens que participaram desta pesquisa apontaram que a sua relação com os homicídios ocorre de três formas: pelo envolvimento com usuários de drogas, adicção de membros da família e tráfico ilegal dessas substâncias. Observa-se que, no imaginário social, a violência é comumente associada aos usuários de drogas, especialmente aos de crack. No entanto, estudiosos das adicções questionam tal relação, afirmando que não há vinculação 
causal entre a produção de violência física e o consumo de substâncias, sejam elas lícitas ou ilícitas. Ressalta-se que os usuários têm em comum vulnerabilidades que os levam à situação de rua e desestruturação dos laços sociais e familiares, acrescidas, ainda, da flagrante ausência de políticas públicas, capazes de intervir nessa realidade com medidas eficazes que não levem a novas exclusões (Alarcon, Jorge, 2012; Pitta, 2011). Quanto ao consumo de drogas por familiares, destacado nesta pesquisa, estudiosos afirmam que é, sobretudo, a atitude permissiva dos pais em relação às drogas que influencia no risco de os filhos se tornarem usuários, pois o comportamento parental lhes serve de modelo (Schenker, Minayo, 2005). Esse imbricamento foi apontado pelos jovens de Paulista como facilitador do envolvimento com crimes e morte.

A principal diferença entre as cidades, no que se refere às drogas, é a presença de grupos organizados do tráfico na região. Paulista apresenta uma condição mais vulnerável, pois possui grupos rivais que dominam o comércio ilegal de drogas. Neste contexto insere-se, ainda, o porte ilegal e o tráfico de armas, ferramentas imprescindíveis na defesa do território e no enfrentamento entre as quadrilhas rivais e dessas com a polícia, a fim de garantir a venda e o consumo das substâncias psicoativas. Essa disputa pelo território e a ilegalidade do produto, aliadas a uma política de segurança repressiva, torna-se um cenário fértil para a ocorrência dos homicídios. Assim, o narcotráfico, atividade altamente rentável, promove o consumo, induz à dependência e incrementa a criminalidade, embora não se possa afirmar que a totalidade dos homicídios decorre dessas atividades ilícitas (Andrade et al., 2011).

Neste cenário é preciso ter-se a clareza de que a violência é inerente às redes de comercialização de drogas ilícitas. Considera-se, então, que as conexões entre drogas e violência, com desdobramento nos homicídios, são complexas, apresentam diversas facetas e suscitam reflexões articuladas com o contexto social, cultural, político e com as características individuais. Cabe, portanto, ampliar a discussão sobre essa temática, uma vez que é inegável que a mudança no padrão de consumo de drogas influencia na forma de organização social, mas não pode ser interpretada como o único e principal problema a ser enfrentado.

No que se refere à dimensão relacional, a valorização dos vínculos familiares em Jaraguá do Sul e a "família desestruturada" em Paulista foram características destacadas pelos depoentes. Neste contexto, estudiosos afirmam ser a família o núcleo de socialização primária no qual se constrói a autoimagem do sujeito por meio de processos identificatórios, sendo responsável pela inserção dos seus membros na cultura (Shenker, 2008; Shenker, Minayo, 2005). Assim, pode-se inferir que as relações familiares são capazes de modular o comportamento de seus membros. Quando os vínculos familiares são positivos e fortes, as chances de manifestação de comportamentos antissociais são menores e essa família se configura como protetora contra os homicídios. Em contraposição, cuidados maternos ou paternos inadequados, vivência em meio à discórdia conjugal e a presença de pais agressivos ou violentos podem resultar no comportamento agressivo de seus membros (Minayo-Gomez, Thedim-Costa,1999). O contato com a violência intrafamiliar na infância e adolescência pode desencadear, na vida adulta, atitudes e comportamentos violentos que reproduzem experiências vivenciadas anteriormente.

Há que se considerar, também, a vulnerabilidade social das famílias em Paulista, que vivem em situações precárias e são comumente responsabilizadas pela miséria, abandono e negligência de suas crianças e adolescentes, e, muitas vezes, pelo envolvimento destes com as drogas e com o crime. Nessa cidade, a renda per capta média é de $\mathrm{R} \$ 507,98$ (US\$250,00), 11,6\% menor que a de Jaraguá do Sul, e $39,6 \%$ da sua população têm baixa renda. Estes indicadores corroboram as precárias condições de vida dos seus moradores, e, neste contexto de vulnerabilidade, estudiosos pontuam que estas famílias enfrentam maiores dificuldades para prover seus filhos das condições materiais de vida que possam protegê-los da violência (Sant'anna, Aers, Lopes, 2005).

Nesta pesquisa, a violência contra a mulher e o abuso sexual evidenciam a necessidade de se trabalharem mudanças do padrão cultural machista, ainda arraigado em ambas as regiões. Em Paulista (8,8/100.000 hab.), a TMH de mulheres foi oito vezes superior à de Jaraguá do Sul (1,4/100.000 hab.) e o dobro da taxa nacional (4,4/100.000 hab.) no ano de 2010, o que suscita uma reflexão acerca dos padrões culturais de gênero. Percebe-se que a ocorrência dos homicídios é também permeada pelas relações de gênero e pelos modelos de masculinidade que associam contradições internas e rupturas históricas, originando diversas masculinidades. Algumas delas podem ocupar um lugar de hegemonia, 
tornando-se o modelo a ser seguido nas relações de gênero, exprimindo uma ideologia em que a masculinidade se baseia na heterossexualidade, na racionalidade e no privilégio de infligir a violência (Souza et al., 2012; Nascimento, Gomes, Rebello, 2009).

Ao se observarem, nas dimensões comunitárias e sociais, as diferenças entre a estrutura e organização do trabalho, percebe-se que há uma forte influência deste na forma de constituição das cidades. A capacidade de o trabalho produzir modos de organização e disciplinarização social e do corpo humano é abordada por diversos autores, que o consideram uma atividade constitutiva do humano (Barros, MinayoGomez, 2002; Dejours, 1992). Ao exercer sua atividade laboral, o homem transforma o mundo, a si próprio e as suas relações com os outros. As dificuldades de inserção profissional e o mal-estar vivenciado nas transformações ocorridas no mundo do trabalho influenciam na definição de si mesmo, fazendo com que ocorra uma crise de identidade. A dimensão profissional interfere na construção e reconstrução de identidades e de trajetórias de vidas, e ganha visibilidade e impacto em um cenário em que o emprego torna-se raro e o mundo do trabalho sofre profundas modificações (Maia, Mancebo, 2010). Os indicadores referentes ao trabalho retratam esta realidade: em Paulista, a proporção da população que exerce atividades laborais sem vínculo formal $(19,25 \%)$ é quase três vezes superior à de Jaraguá do Sul $(7,10 \%)$. Assim, os modos de organização do trabalho e sua repercussão nas trajetórias dos indivíduos e de suas identidades se mostram nas duas cidades de forma bastante ilustrativa.

No que se refere à rede pública de ensino, em 2010, verificava-se que $17,14 \%$ dos estudantes em Paulista a frequentavam. Em Jaraguá do Sul esta proporção era de $22,09 \%$, o que reforça a maior credibilidade dos seus moradores na educação pública. A precária oferta de educação formal em Paulista, tal como mencionado pelos jovens, compromete a função da escola enquanto agente transformador, protetor e de aprendizagem. Os problemas apontados, sobretudo no ensino público, destituem a escola de atrativos que acabam por desmotivar os jovens a frequentá-la. Na sociedade atual, a escola se constitui como um valor pela função que desempenha, tendo em vista a necessidade da educação formal na socialização dos indivíduos e sua integração nas formas de subsistência. No entanto, esse importante espaço reflete o sistema excludente e a reprodução das desigualdades sociais no momento em que não se conforma em campo de oportunidades e garantias universais (Cocco, Lopes, 2010).

Quanto às questões de segurança pública, a falta de confiança na polícia, a corrupção de membros dessa corporação e a presença de grupos armados ligados ao tráfico de drogas e às milícias comprometem a circulação urbana dos moradores de Paulista, que compreendem não ter a quem recorrer em casos extremos, e buscam soluções individuais, muitas vezes, pela via da violência. Em Jaraguá, parte dos entrevistados afirmou que a população estabelece controle social e vigilância permanentes quanto às questões de segurança pública. A polícia é constantemente informada pelos moradores de ações suspeitas nos espaços privados e públicos, o que reprime as ações delituosas e reduz as possibilidades de impunidade. Ressalta-se que a polícia é a linha de frente do controle da desordem social, em função da sua rede territorial, sua capacidade de lidar com as emergências e seus poderes legais (Silva Filho, Gall, 2002). No entanto, o desvio para as atividades ilícitas cometidas por policiais desperta a desconfiança e o sentimento de insegurança do cidadão diante de sua polícia.

Neste contexto, a religiosidade foi apontada como possibilidade de proteção para os homicídios. Estudiosos afirmam que esta poderia auxiliar na construção da personalidade do indivíduo por meio dos fundamentos pregados, incutindo-lhe valores morais que têm por fim o respeito e a preservação da vida, podendo proteger o indivíduo de transtornos de condutas violentas (Cruzeiro et al., 2008; Sanchez, Oliveira, Nappo, 2004). A religiosidade pode ser ainda considerada como componente da rede de apoio, fortalecendo o capital social das comunidades, colaborando na prevenção da violência.

\section{Conclusão}

Diante desta análise, pode-se afirmar que o Modelo Ecológico constitui uma ferramenta importante para a compreensão dos homicídios ao adotar uma visão sistêmica que considera as condições individuais, relacionais, comunitárias e sociais do contexto em que estes ocorrem, o que representa um 
avanço para o conhecimento. Como limite, pode-se apontar a impossibilidade de generalização dos achados desta pesquisa, uma vez que cada município apresenta condições peculiares que merecem aprofundamento.

No caso de Paulista, relacionando-se os indicadores sociais aos relatos dos sujeitos, percebe-se uma sobreposição de vulnerabilidades econômicas e sociais, como: baixa escolaridade, uso de drogas e envolvimento com o tráfico, fragilidade dos vínculos familiares e violência intrafamiliar, desemprego e precariedade da educação e segurança públicas. Tais condições aprofundam as situações de exclusão social dos sujeitos, conformando um terreno fértil para a violência letal. Já em Jaraguá do Sul, os indicadores socioeconômicos mostram melhores condições de vida, e os relatos evidenciam um contexto social em que há: fortes vínculos familiares, acesso à educação, emprego, confiança nas instituições e maior consciência da importância delas e de um controle social que acabam por inibir as situações de violência. Neste último município, as falas dos sujeitos apontam a violência letal como resultado de ações passionais ou endividamentos.

Destaca-se que, em ambos os municípios, o consumo de drogas e o narcotráfico permearam todas as dimensões do modelo ecológico, sendo apontados como as principais causas dos homicídios. Essas percepções, forjadas no imaginário social com a forte contribuição da mídia e das abordagens repressivas por parte da segurança pública, parecem ocultar questões mais complexas relacionadas à cultura machista e a questões étnicas discriminatórias presentes em Jaraguá do Sul. Por outro lado, também encobrem as precárias condições socioeconômicas que levam grande parcela da população de Paulista à exclusão. Assim, a abordagem ao fenômeno das drogas nos municípios reproduz um modelo cultural de exclusão focado nos usuários, e, como um tema de grande apelo social, parece camuflar processos sociais mais complexos, relacionados, sobretudo, à exclusão de parcelas específicas da população.

Conclui-se que a determinação dos homicídios parece ser permeada por um contexto que envolve a combinação de: vulnerabilidades, fragilidades, precariedades e rupturas de vínculos na dimensão individual e na vida social. No entanto, essas condições adversas são passíveis de ações de prevenção e enfrentamento que devem incluir a família, a escola e a comunidade, além de empenharem esforços no sentido de reduzir a exclusão e as desigualdades sociais. Tais ações devem ser implementadas em uma perspectiva inclusiva, interdisciplinar e intersetorial, com vistas à construção da cidadania.

\section{Colaboradores}

Juliana Guimarães e Silva, Fabiana Castelo Valadares e Edinilsa Ramos de Souza participaram, igualmente, de todas as etapas de elaboração do artigo.

\section{Agradecimentos}

Ao CNPq, pelo apoio dado ao estudo, por meio do INCT Violência, Democracia e Segurança Cidadã.

\section{Referências}

ALARCON, S.; JORGE, M.A.S. Álcool e outras drogas: diálogos sobre um mal-estar contemporâneo. Rio de Janeiro: Ed. Fiocruz, 2012.

ANDRADE, S.M. et al. Homicídios de homens de quinze a 29 anos e fatores relacionados no estado do Paraná, de 2002 a 2004. Cienc. Saude Colet., v.16, supl.1, p.1281-8, 2011. 
BARROS, M.E.B.; MINAYO-GOMEZ, C. Saúde, trabalho e processos de subjetivação nas escolas. Psicol. Reflex. Crit., v.15, n.3, p.24-52,2002.

BRICEÑO-LEON, R. Urban violence and public health in Latin America: a sociological explanatory framework. Cad. Saude Publica, v.21, n.6, p.1629-64, 2005.

La nueva violencia urbana de América Latina. Sociologias, v.4, n.8, 34-51, 2002.

CAVALCANTE, F.G.; SCHENKER, M. Violência, família e sociedade. In: NJAINE, K.; ASSIS, S.G.; CONSTANTINO, P. (Orgs.). Impactos da violência na saúde. Rio de Janeiro: Ed. Fiocruz, 2009. p.57-79.

COCCO, M.; LOPES, M.J.M. Violência entre jovens: dinâmicas sociais e situações de vulnerabilidade. Rev. Gaucha Enferm., v.31, n.1, p.151-9, 2010.

CRUZEIRO, A.L.S. et al. Prevalência e fatores associados ao transtorno da conduta entre adolescentes: um estudo de base populacional. Cad. Saude Publica, v.24, n.9, p.2013-20, 2008.

DEJOURS, C. A loucura do trabalho: estudo de psicopatologia do trabalho. São Paulo: Cortez, Oboré, 1992.

DUARTE, E.C. et al. Associação ecológica entre características dos municípios e o risco de homicídios em homens adultos de 20-39 anos de idade no Brasil, 1999-2010.

Cienc. Saude Colet., v.17, n.9, p.2259-68, 2012.

INSTITUTO BRASILEIRO DE GEOGRAFIA E ESTATÍSTICA. Censo 2010. Disponível em: <http://www.sidra.ibge.gov.br/cd/cd2010universo.asp?o $=7 \& \mathrm{i}=\mathrm{P}>$. Acesso em: 11 nov. 2012.

LUHMANN, N. System as difference. Organization, v.3, n.1, p.37-57, 2006.

MAIA, A.A.R.M.; MANCEBO, D. Juventude, trabalho e projetos de vida: ninguém pode ficar parado. Psicol. Cienc. Prof., v.30, n.2, p.376-89, 2010.

MENEGUEL, S.N.; HIRAKATA, V.N. Femicídios: homicídios femininos no Brasil. Rev. Saude Publica, v.45, n.3, p.564-74, 2012.

MINAYO, M.C.S. O desafio do conhecimento: pesquisa qualitativa em saúde. São Paulo: Hucitec, 2006.

MINAYO, M.C.S.; ASSIS, S.G.; SOUZA, E.R. Avaliação por triangulação de métodos: abordagem de programas sociais. Rio de Janeiro: Ed. Fiocruz, 2005.

MINAYO-GOMEZ, C.; THEDIM-COSTA, S.M.F. Precarização e desproteção social: desafios para a saúde coletiva. Cienc. Saude Colet., v.4, n.2, p.411- 21,1999.

NASCIMENTO, E.F.; GOMES, R.; REBELLO, L.E.F.S. Violência é coisa de homem? A "naturalização" da violência nas falas dos homens jovens. Cienc. Saude Colet., v.14, n.4, p.1151-7, 2009.

ORGANIZAÇÃO MUNDIAL DE SAÚDE. Relatório mundial sobre violência e saúde. Genebra: OMS, 2002.

PERES, M.F.T. et al. Queda dos homicídios no Município de São Paulo: uma análise exploratória de possíveis condicionantes. Rev. Bras. Epidemiol., v.14, n.4, p.709-21, 2011.

Evolução dos homicídios e indicadores de segurança pública no Município de São Paulo entre 1996 a 2008: um estudo ecológico de séries temporais. Cienc. Saude Colet., v.17, n.12, p.3249-57, 2012.

PITTA, A.M.F. Um balanço da reforma psiquiátrica brasileira: instituições, atores e políticas. Cienc. Saude Colet., v.16, n.12, p.4579-89, 2011.

REICHENHEIM, M.E. et al. Violência e lesões no Brasil: efeitos, avanços alcançados e desafios futuros. Lancet, v.6736, n.11, p.75-89, 2011. 
SÁ, S.D.; WERLANG, B.S.G. Homicídio seguido de suicídio na cidade de Porto Alegre. Est. Psicol., v.24, n.2, p.181-9, 2007.

SANCHEZ, Z.V.M.; OLIVEIRA, L.G.; NAPPO, A.S. Fatores protetores de adolescentes contra o uso de drogas com ênfase na religiosidade. Cienc. Saude Colet., v.9, n.1, p.43-55, 2004.

SANT'ANNA, A.R.; AERTS, D.; LOPES, M.J. Homicídios entre adolescentes no Sul do Brasil: situações de vulnerabilidade segundo seus familiares. Cad. Saude Publica, v.21, n.1, p.120-9, 2005.

SCHENKER, M. Valores familiares e uso abusivo de drogas. Rio de Janeiro: Editora Fiocruz, 2008.

SCHENKER, M.; MINAYO, M.C.S. Fatores de risco e de proteção para o uso de drogas na adolescência. Cienc. Saude Colet., v.10, n.3, p.707-17, 2005.

SILVA FILHO, J.V.; GALL, N. A polícia - incentivos perversos e segurança pública. In: OLIVEIRA, N.V. (Org.). Insegurança pública: reflexões sobre a criminalidade e a violência urbana. São Paulo: Nova Alexandria, 2002. p.200-20.

SOUZA, E.R.; LIMA, M.L.C.; BEZERRA, E.A.D. Homicides in Brazil: evolution and impacts. In: LOVISI, G.M.; MARI, J.J.; VALENCIA, E.S. (Orgs.). The psychological impact of living under violence and poverty in Brazil. New York: Nova Science Publisher Inc., 2010. p.1-14.

SOUZA, E.R. et al. Morbimortalidade de homens jovens brasileiros por agressão: expressão dos diferenciais de gênero. Cienc. Saude Colet., v.17, n.12, p.3243-8, 2012.

UNITED NATIONS OFFICE ON DRUGS AND CRIME. Global study on homicide: trends, contexts, data. Vienna: UNODC, 2011.

WAISELFISZ, J.J. Mapa da violência 2012: os novos padrões da violência homicida no Brasil. São Paulo: Instituto Sangari, 2011.

GUIMARÃES E SILVA, J.G.; VALADARES, F.C.; SOUZA, E.R. El desafío de comprender la consecuencia fatal de la violencia en dos municipios brasileños. Interface (Botucatu), v.17, n.46, p.535-47, jul./set. 2013.

Buscamos comprender los homicidios por medio del abordaje sistémico complejo, abordando el Modelo Ecológico (ME), que envuelve condiciones individuales y relacionales de los sujetos y del contexto. Se realizaron dos estudios de caso triangulando datos cuantitativos y cualitativos. Los municipios seleccionados Paulista, Pernambuco, y Jaraguá do Sul, en el Estado de Santa Catarina, mostraron un comportamiento opuesto a las tasas de homicidio entre 1980 y 2007 . El análisis cualitativo mostró en cada dimensión del modelo ecológico: individual: bajo nivel educativo y consumo de drogas; relacional: violencia intrafamiliar y consumo de drogas por miembros de la familia; comunitario y social: trabajo y desempleo; educación pública; seguridad pública; tráfico de drogas y religiosidad. Se concluye que los homicidios envuelven una combinación de vulnerabilidad, precariedad y ruptura de vínculos en la dimensión individual y social, que pueden enfrentarse en una perspectiva incluyente, interdisciplinaria e intersectorial.

Palabras clave: Homicidio. Estudio de Caso. Violencia. Vulnerabilidad social. 
